\title{
Biochemical Recurrence After Radical Prostatectomy: is the Disease or the Surgeon to Blame?
}

\author{
Adnan Sımsır, Cag Cal, Rashad Mammadov, Ibrahim Cureklıbatır, Bulent Semercı, Gurhan \\ Gunaydın
}

Ege University Medical Faculty Department of Urology, Izmir, Turkey

\begin{abstract}
Purpose: The PSA recurrence develops in 27 to 53\% within ten years after radical prostatectomy (RP). We investigated the factors (disease grade and stage or the surgeon's expertise,) more likely to influence biochemical recurrence in men post-radical prostatectomy for organ-confined prostate cancer by different surgeons in the same institution.

Materials and Methods: A total of 510 patients that underwent radical prostatectomy were investigated retrospectively. Biochemical recurrence was defined as detection of a PSA level of $\geq 0.20 \mathrm{ng} / \mathrm{mL}$ by two subsequent measurements. The causes, which are likely to influence the development of PSA recurrence, were separated into two groups as those related to the disease and those related to the surgical technique.

Results: Biochemical recurrence was detected in 23.5\% (120 cases) of 510 cases. The parameters most likely to influence biochemical recurrence were: PSA level $(p<0.0001)$, T stage $(p<0.0001)$, the presence of extracapsular invasion prostate $(\mathrm{p}<0.0001)$, Gleason scores $(\mathrm{p}=0.042, \mathrm{p}<0.0001)$ and the presence of biopsy with perineural invasion $(\mathrm{p}=0.03)$. The only surgical factor that demonstrated relevance was inadvertent capsular incision during the surgery that influenced the PSA recurrence $(\mathrm{p}<0.0001)$.

Conclusion: The PSA recurrence was detected in $21.6 \%$ of patients who had been treated with radical prostatectomy within 5 years, which indicates that the parameters related to the disease and the patient have a pivotal role in the PSA recurrence.
\end{abstract}

Key words: prostatectomy; prostate cancer; recurrence; prostate-specific antigen

Int Braz J Urol. 2011; 37: 328-335

\section{INTRODUCTION}

Radical prostatectomy (RP) continues to be the "gold standard" in the treatment of localized prostate cancer for patients with a life expectancy of 10 years (1). However, biochemical recurrence may occur in 27 to $53 \%$ within ten years after radical prostatectomy (RP) (1-3) and additional treatment may be required in $35 \%$ of these patients $(1,3)$. High pretreatment levels of PSA, high grade Gleason score, advanced clinical and pathological stage and positive surgical margin (PSM) have been proven to be independent predictors of biochemical recurrence post-prostatectomy $(4,5)$. Most of these predictors are related with the disease characteristics. Thus, the
PSA recurrence appears to be related to the disease itself rather than the surgery performed in patients who underwent RP. In the present study, we investigated possible causes that may influence biochemical recurrence in post RP men treated for localized prostate cancer performed by different surgeons in the same medical center.

\section{MATERIALS AND METHODS}

A total of 602 patients who were diagnosed with clinic localized prostate cancer and underwent retropubic RP between May 1998 and April 2009 were retrospectively studied. Ninety two patients were excluded from the study due to positive lymph 
node metastases or lost follow-up. Following the EAU Guidelines on Prostate Cancer, the follow-up was conducted 3, 6 and 12 months post-prostatectomy during the first year, and every six months in the second year and thereafter with PSA level and digital rectal exam. PSA level $\geq 0.20 \mathrm{ng} / \mathrm{mL}$ by two subsequent measurements was defined as biochemical recurrence. We analyzed factors related to the disease or the surgery that may influence PSA recurrence (Table-1).

Ten different surgeons performed the operations in accordance with the technique described by Walsh (6). A modified pelvic lymph node dissection was performed in all patients. Surgical samples were stained with India ink in order to determine surgical margins and fixed with $10 \%$ formalin. Whole mount prostate and seminal vesicle examination was performed at intervals of 2-3mm.

PSM was defined as neoplastic cells in contact with inked surgical margin (7).

All statistical analysis was performed via SPSS 13 program and $p$ value of $\leq 0.05$ was considered statistically significant. Chi-square test, Student T-test, Logistic Regression and Multivariate analyses were used to examine correlation of variables and the PSA recurrence. Time of PSA free progression and its relationship with the variables were analyzed by Kaplan-Meier curve.

\section{RESULTS}

The mean follow-up was 89 months (12114 months) and biochemical recurrence was detected in $120(23.5 \%)$ of 510 patients. The time of the biochemical recurrence was observed to be 29.02 months (7-82 months) in average.

Group 1: The variables which are considered to be related to the disease and patient were investigated in this group.

Patients mean age was 67 years old (43-81 y.o.) and no statistically significant relationship was detected between this variable and biochemical recurrence by univariate analysis $(\mathrm{p}=0.36)$.

The mean preoperative PSA level was 11.1 $\mathrm{ng} / \mathrm{dL}(0.32-65 \mathrm{ng} / \mathrm{dL})$ and a statistically significant relationship was observed between the PSA levels and biochemical recurrence. It was also observed that the rate of the recurrence was $14.9 \%$ in patients with a PSA level $\leq 11.1 \mathrm{ng} / \mathrm{dL}$ and $36 \%$ in those $>$ $11.1 \mathrm{ng} / \mathrm{dL}(\mathrm{p}<0.0001)$.

Likewise, strong correlation between the pathological stage and progression of the disease was detected. The rate of the biochemical recurrence was $56.9 \%$ in 128 patients who were considered to be cT2 prostate cancer but then observed to be pT3a (extraprostatic extension) whereas $18.2 \%$ in 318 patients with organ-confined (pT2) disease $(\mathrm{p}<$ 0.0001).

The mean rate of PSA recurrence was $44.4 \%$ in patients with a Gleason score of 7 and above whereas $11.2 \%$ in those with a score of 6 and below $(p=0.042)$. Similarly, the rate of biochecmical recurrence in the surgical sample was $52.6 \%$ in patients with a Gleason $>7$, and $15.5 \%$ in those with Gleason $<6(p<0.0001)$.

The rate of PSA progression was $34.7 \%$ in 192 patients whose biopsy sample analysis revealed perineural invasion (PNI) whereas $19.4 \%$ in patients without PNI $(\mathrm{p}=0.03)$. Additionally, significant correlations between the presence of PNI in biopsy and PSM $(p<0.001)$, pT stage $(p<0.001)$, extraprostatic tumor extension $(\mathrm{p}<0.001)$, and preoperative PSA level $(\mathrm{p}<0.014)$ were detected. Although PSA recurrence was observed in $29.6 \%$ of patients with PNI in surgical specimen (356 patients), the percentage was only 20.9 in patients without PNI $(p=0.092)$.

Similar results were obtained when we analyzed the PSA free progression 5 year-survival and parameters regarding the disease and patient using the Kaplan-Meier method (Table-2).

Group 2: The parameters related to the surgical treatment (surgeon's expertise).

It was observed that a PSM occurred due capsular incision during the dissection in 119 (23.3\%) of 510 patients who underwent RP. The rate of biochemical recurrence was detected to be $56.6 \%$ in the patients of this group $(\mathrm{p}<0.0001)$. It was observed that the mean blood loss was $420 \mathrm{cc}(50-2500 \mathrm{cc})$ and there was no statistically significant finding between the blood loss and PSA recurrence $(p=0.24)$.

Walsh suggested to wait at least 6 weeks for tissue repair after the biopsy and then to perform RP (5). In the present study, we analyzed patients who had been operated before and after the 6 week period 
Table 1 - PSA recurrence groups.

\begin{tabular}{lc}
\hline Group 1 & Group 2 \\
\hline parameters related to the disease & parameters related to the surgical technique and/or patient \\
Age & Estimated Blood Loss \\
Pre operative PSA level & Positive surgical margin \\
Gleason Sum & Time between biopsy and RP \\
Extraprostatic extension & Surgical experience \\
Prostate weight & \\
Perineural invasion & \\
T stage & \\
\hline
\end{tabular}

post-biopsy, and the results did not attain statistical significance $(p=0.36)$.

Each of 10 surgeons operated on 51 patients (32-188 patients) in average whereas, no statistically significant relationship was observed between the surgeons and PSA progression $(p=0.18)$. Additionally, when number of procedures/surgeon and PSA progression was studied no statistically difference was observed $(p=0.16)$ even for the surgeon with the highest number of operations (188 cases). However, the rate of tumor incision by the surgeon with the highest number of operations was $17.02 \%$ whereas, the remaining nine surgeons was $27.01 \%$ $(\mathrm{p}=0.026)($ Table-3). On the other hand, the rate of EPE was $32.9 \%$ in patients operated on by one surgeon whereas it was $20.5 \%$ in those operated on by the remaining 9 surgeons $(\mathrm{p}=0.032)$. Table- 4 summarizes the rates of 5-year survival without PSA progression and their relationships with other parameters related to the surgery.

While multivariate analysis showed positive correlations between biochemical recurrence and PSM $(\mathrm{p}=0.042)$, preoperative PSA level $(\mathrm{p}=$ $0.002)$, and $\mathrm{pT}$ stage $(\mathrm{p}=0.002)$, the most significant predictor for the recurrence was found to be with PSM.

\section{DISCUSSION}

The most common predictors of biochemical recurrence after radical prostatectomy are high pre-treatment levels of PSA, Gleason score, clinical tumor stage, pathological stage, and PSM (8-10). In our study, pre-surgery PSA level, clinical and pathological T stage, PSM, biopsy and surgical specimen Gleason score and the presence of biopsy perineural invasion were determined to be factors that correlated with PSA recurrence.

PSM is directly associated with biochemical recurrence after RP. PSM is defined as tumor at the inked margin of the excised specimen (7,11-13). Wieder and Soloway reported that the rate of PSM was $22.5 \%$ (12) in organ-confined disease. In the present study, PSM is evident in $23.3 \%$ of patients with organ-confined disease.

The incision of the tumor in patients with organ-confined disease is undoubtedly an important parameter related to surgical experience, which correlates with PSA recurrence $(9,14)$. Felix et al. compared the results of one surgeon with the highest number of RP operations with other 10 surgeons and found that rates of PSA recurrence and PSM of the surgeon with the highest number of operations were significantly lower (15). Similar results were obtained in other studies (16-19). In the present study, when the results of the surgeon with the highest number of operations (188 cases) were compared to the remaining 9 surgeons, the PSM rates were observed to be consistent with the literature. On the other hand, it was found that the rate of biochemical recurrence was not correlated with surgical experience. The effect of individual experience of the surgeon on the success of surgery is controversial. In the present study, the comparison between surgeons 
Table 2 - Association of Group $1 *$ with the PSA recurrence.

\begin{tabular}{|c|c|c|}
\hline & Progression free survival rate ${ }^{* *}(\%)$ & P value \\
\hline \multicolumn{3}{|l|}{ Age } \\
\hline$<70$ & 38.4 & \\
\hline$\geq 70$ & 43.2 & 0.260 \\
\hline \multicolumn{3}{|l|}{ PSA (ng/dL) } \\
\hline$<10$ & 56.1 & \\
\hline$\geq 10$ & 12.8 & $<0.0001$ \\
\hline \multicolumn{3}{|l|}{ Gleason sum } \\
\hline$<7$ & 62.3 & \\
\hline$\geq 7$ & 12.0 & $<0.0001$ \\
\hline \multicolumn{3}{|c|}{ Extraprostatic extension } \\
\hline Yes & 12.7 & \\
\hline No & 66.4 & $<0.0001$ \\
\hline \multicolumn{3}{|c|}{ Prostate weight (gr) } \\
\hline$<50$ & 36.4 & \\
\hline$\geq 50$ & 48.2 & 0.092 \\
\hline \multicolumn{3}{|c|}{ Presence of perineural invasion } \\
\hline Yes & 22.9 & \\
\hline No & 44.1 & 0.043 \\
\hline \multicolumn{3}{|l|}{ pT stage } \\
\hline $\mathrm{T} 2$ & 78.4 & \\
\hline $\mathrm{T} 3$ & 17.9 & $<0.0001$ \\
\hline
\end{tabular}

* The parameters related to the disease and patient.

** For five years, analyzed by Kaplan-Meier Method.

(highest number of operations and other surgeons) revealed no significant differences. However, differences in EPE rates were noted. The capsular incision rate of the surgeon with the highest number of RP was significantly lower than other surgeons, whereas, EPE rates for the same surgeon were significantly higher, which may be explained by the selection bias of higher complexity and clinical stage patients for the most experienced surgeon.

The relation between PNI in biopsy specimen and biochemical recurrence is controversial.
Although PNI in radical prostatectomy specimen is very common, there is no clear evidence between PNI and disease progression yet, which is also demonstrated in our study. However, the correlation between PNI in biopsy specimen and biochemical recurrence was detected, although the reasons are not known. The PNI in biopsy specimen could be a predictor to determine the tumor aggressiveness $(20,21)$, since strong correlation between PNI in the biopsy specimen and PSM, pathological T stage, EPE, and preoperative PSA level were found in our study. 
Table 3 - Results Comparison between the surgeon with the highest number of radical prostatectomies and others.

\begin{tabular}{lccc}
\hline & $\begin{array}{c}\text { The surgeon with the } \\
\text { highest number of } \\
\text { operations }\end{array}$ & Other surgeons \\
\hline No. of patients & 188 & & \\
Age & 60.12 & 322 & 0.22 \\
PSA(ng/dL) & 16.02 & 66.16 & 0.03 \\
Prostat weight (g) & 57.49 & 08.02 & 0.83 \\
Gleason Sum & 7.29 & 50.76 & 0.61 \\
T stage & & 7.02 & \\
\multicolumn{1}{c}{ pT2a } & $18(9.6 \%)$ & & 0.82 \\
\multicolumn{1}{c}{ pT2b } & $28(15.5 \%)$ & $40(12.4 \%)$ & 0.65 \\
\multicolumn{1}{c}{ pT2c } & $60(31.9 \%)$ & $64(19.8 \%)$ & 0.54 \\
\multicolumn{1}{c}{ pT3b } & $62(32.9 \%)$ & $108(33.5 \%)$ & 0.03 \\
PNI $^{1}$ & $20(10.1 \%)$ & $66(20.5 \%)$ & 0.19 \\
PSM $^{2}$ & $74(39.3 \%)$ & $44(13.8 \%)$ & 0.87 \\
EPE $^{3}$ & $32(17.0 \%)$ & $87(27.0 \%)$ & 0.02 \\
PSA recurrence $^{4}$ & $62(32.9 \%)$ & $66(20.5 \%)$ & 0.03 \\
\hline
\end{tabular}

Student T-Test and Pearson Chi square test used. / 1:Perineural invasion in biopsy; 2:Positive surgery margin; 3:Extraprostatic extension; 4:Number of patients with PSA recurrence

Table 4 - The association of Group $2 *$ with the PSA recurrence.

Progression free
survival rate**(\%) $\quad$ P value

\section{Estimated Blood Loss (cc)}

$$
\begin{aligned}
& <1000 \\
& \geq 1000
\end{aligned}
$$

Capsular incision

Yes

No

Time between biopsy \& RP (weeks)

$$
<6
$$$$
\geq 6
$$

Surgical Experience

The surgeon with the highest Other Surgeons

\section{3}

73.1

50.1

62.7

0.590

number of operations

68.1

46.2

* The parameters related to the surgical technique./ ** For five years, analyzed by Kaplan-Meier Method. 


\section{CONCLUSIONS}

Among the causes related to the surgical technique, which influence the biochemical recurrence, only PSM due to capsular incision is of importance. Although the surgeon's "factor" did not attain statistical significance, the significant relationship between the number of patients the surgeon operated on and rates of capsular incision indicates the importance of surgical experience. However, the clinical outcome after surgery for the treatment of clinically localized prostate cancer appears to be more related to the aggressiveness of the disease than surgeon's expertise alone.

\section{CONFLICT OF INTEREST}

None declared.

\section{REFERENCES}

1. Amling CL, Blute ML, Bergstralh EJ, Seay TM, Slezak J, Zincke H: Long-term hazard of progression after radical prostatectomy for clinically localized prostate cancer: continued risk of biochemical failure after 5 years. J Urol. 2000; 164: 101-5.

2. Billis A, Magna LA, Lira MM, Moreira LR, Okamura H, Paz AR, et al.: Relationship of age to outcome and clinicopathologic findings in men submitted to radical prostatectomy. Int Braz J Urol. 2005; 31: 534-9; discussion 539-40.

3. Pound CR, Partin AW, Eisenberger MA, Chan DW, Pearson JD, Walsh PC: Natural history of progression after PSA elevation following radical prostatectomy. JAMA. 1999; 281: 1591-7.

4. Kattan MW, Wheeler TM, Scardino PT: Postoperative nomogram for disease recurrence after radical prostatectomy for prostate cancer. J Clin Oncol. 1999; 17: 1499-507.

5. Hull GW, Rabbani F, Abbas F, Wheeler TM, Kattan MW, Scardino PT: Cancer control with radical prostatectomy alone in 1,000 consecutive patients. J Urol. 2002; 167: 528-34.

6. Walsh PC: Anatomic radical prostatectomy: evolution of the surgical technique. J Urol. 1998; 160: 2418-24.

7. Voges GE, McNeal JE, Redwine EA, Freiha FS, Stamey TA: Morphologic analysis of surgical mar- gins with positive findings in prostatectomy for adenocarcinoma of the prostate. Cancer. 1992; 69: 520-6.

8. Chun FK, Briganti A, Antebi E, Graefen M, Currlin E, Steuber T, et al.: Surgical volume is related to the rate of positive surgical margins at radical prostatectomy in European patients. BJU Int. 2006; 98: 1204-9.

9. Ward JF, Zincke H, Bergstralh EJ, Slezak JM, Myers RP, Blute ML: The impact of surgical approach (nerve bundle preservation versus wide local excision) on surgical margins and biochemical recurrence following radical prostatectomy. J Urol. 2004; 172: 1328-32.

10. Stamey TA, Villers AA, McNeal JE, Link PC, Freiha FS: Positive surgical margins at radical prostatectomy: importance of the apical dissection. J Urol. 1990; 143: 1166-72; discussion 11723.

11. Ohori M, Wheeler TM, Kattan MW, Goto Y, Scardino PT: Prognostic significance of positive surgical margins in radical prostatectomy specimens. J Urol. 1995; 154: 1818-24.

12. Wieder JA, Soloway MS: Incidence, etiology, location, prevention and treatment of positive surgical margins after radical prostatectomy for prostate cancer. J Urol. 1998; 160: 299-315.

13. Watson RB, Civantos F, Soloway MS: Positive surgical margins with radical prostatectomy: detailed pathological analysis and prognosis. Urology. 1996; 48: 80-90.

14. Swindle P, Eastham JA, Ohori M, Kattan MW, Wheeler T, Maru N, et al.: Do margins matter? The prognostic significance of positive surgical margins in radical prostatectomy specimens. J Urol. 2005; 174: 903-7.

15. Chun FK, Briganti A, Antebi E, Graefen M, Currlin E, Steuber T, et al.: Surgical volume is related to the rate of positive surgical margins at radical prostatectomy in European patients. BJU Int. 2006; 98: 1204-9.

16. Birkmeyer JD, Stukel TA, Siewers AE, Goodney PP, Wennberg DE, Lucas FL: Surgeon volume and operative mortality in the United States. N Engl J Med. 2003; 349: 2117-27.

17. Begg CB, Riedel ER, Bach PB, Kattan MW, Schrag $\mathrm{D}$, Warren JL, et al.: Variations in morbidity after radical prostatectomy. N Engl J Med. 2002; 346: 1138-44.

18. Hu JC, Gold KF, Pashos CL, Mehta SS, Litwin MS: Role of surgeon volume in radical prostatec- 
tomy outcomes. J Clin Oncol. 2003; 21: 401-5.

19. Shah A, Okotie OT, Zhao L, Pins MR, Bhalani V, Dalton DP: Pathologic outcomes during the learning curve for robotic-assisted laparoscopic radical prostatectomy. Int Braz J Urol. 2008; 34: 159-62; discussion 163 .

20. de la Taille A, Rubin MA, Bagiella E, Olsson CA, Buttyan R, Burchardt T, et al.: Can perineural invasion on prostate needle biopsy predict prostate specific antigen recurrence after radical prostatectomy? J Urol. 1999; 162: 103-6.

21. Quinn DI, Henshall SM, Brenner PC, Kooner R, Golovsky D, O'Neill GF, et al.: Prognostic significance of preoperative factors in localized prostate carcinoma treated with radical prostatectomy: importance of percentage of biopsies that contain tumor and the presence of biopsy perineural invasion. Cancer. 2003; 97: 1884-93.
Accepted after revision:

September 19, 2010

\section{Correspondence address:}

Dr. Adnan Simsir

Department of Urology

Ege University Medical Faculty, Izmir, Turkey

EUTF Hastanesi Uroloji AD 4

Kat Bornova, 35100, Izmir, Turkey

Fax:+ 0090232 374-6552

E-mail: adnan.simsir@ege.edu.tr

\section{EDITORIAL COMMENT}

Biochemical recurrence (BR) after radical prostatectomy has been described up to $50 \%$ after 10 years of follow up. The problem is to identify which parameters are important in the determination of the recurrence in order to introduce adjuvant therapies for better overall survival rate. PSA levels, Gleason score and tumor stage are the main factors, but in times of prostate cancer screening most patients have clinically localized tumors, PSA lower than 10 and intermediate Gleason score. Among these patients positive surgical margins is the main factor related to $\mathrm{BR}$ as illustrated in this paper. But even in this specific situation some studies have demonstrated $70 \%$ of recurrence free survival. Who is the patient that deserves to be treated with adjuvant therapy? Some specific aspects have been considered as positive surgical margins and the Gleason score $(1,2)$. This is an open field to better understand the behavior of prostate cancer and certainly, it deserves attention from the scientific community. The pivotal question is how to determine the patients taht derserve treatment versus overtreatment. 


\section{REFERENCES}

1. Cao D, Kibel AS, Gao F, Tao Y, Humphrey PA: The Gleason score of tumor at the margin in radical prostatectomy is predictive of biochemical recurrence. Am J Surg Pathol. 2010; 34: 994-1001.
2. Emerson RE, Koch MO, Jones TD, Daggy JK, Juliar BE, Cheng L: The influence of extent of surgical margin positivity on prostate specific antigen recurrence. J Clin Pathol. 2005; 58: 1028-32.

Dr. Katia Ramos Moreira Leite Genoa Biotecnologia

Laboratório de Investigação Médica da Disciplina de Urologia FMUSP - LIM55

Laboratório de Patologia Cirúrgica e Molecular - HSL

E-mail:katiaramos@uol.com.br 